\title{
Identifying and prioritizing the factors affecting the Iranian Sports Refereeing Ethics Code
}

\section{Identificando y priorizando los factores que influyen en el Código de Ética del Arbitraje Deportivo de Irán}

\author{
Ahdieh Sadeghi Kalani ${ }^{1}$, Shirin Zardoshtian ${ }^{2 *}$, Shahab Bahrami ${ }^{1}$, Masoud Sadeghi ${ }^{3}$ \\ ${ }^{1}$ Department of Sports Management, Kermanshah Branch, Islamic Azad University, Kermanshah, \\ Iran \\ ${ }^{2}$ Faculty of Physical Education, Razi University, Kermanshah, Iran \\ ${ }^{3}$ Medical Ethics Department, Kermanshah University of Medical Sciences, Kermanshah, Iran \\ * Correspondence: Shirin Zardoshtian; zardoshtian2014@gmail.com
}

\begin{abstract}
The purpose of this research was to compile a sports refereeing ethics code in Iran. The method of the present research was mixed (qualitative and quantitative). A total of 15 experts in the field of refereeing ethics in sports were interviewed by the method of snowball sampling. The results obtained from the interview led to a valid and reliable questionnaire that was randomly distributed among the referees and assistant referees of the Iranian premier leagues of team sports (football, volleyball, handball and basketball) and individual sports (taekwondo, karate, wrestling and swimming), with a total sample of 224 people. Analysis and coding were performed using the softwares Max Kyoda, SPSS and Smart PLS. Research findings showed that 8 themes and 61 sub-themes were extracted in this field, which include the components of behavior, corruption, communication, sociocultural aspect, family, respect, legality and justice, in this order of importance. In general, paying attention to the behavioral and corruption aspects plays an important role in improving the ethical status of sports referees in Iran.
\end{abstract}

\section{KEYWORDS}

Ethics; Refereeing; Sports; Iran. 


\section{RESUMEN}

El propósito de esta investigación fue compilar un código de ética del arbitraje deportivo en Irán. El método de la presente investigación fue mixto (cualitativo y cuantitativo). Se entrevistó a un total de 15 expertos en el campo de la ética del arbitraje deportivo mediante el método de muestreo de bola de nieve. Los resultados obtenidos en la entrevista dieron lugar a un cuestionario válido y fiable que se distribuyó aleatoriamente entre los árbitros y árbitros asistentes de las principales ligas iraníes de deportes de equipo (fútbol, voleibol, balonmano y baloncesto) y deportes individuales (taekwondo, kárate, lucha libre y natación), con una muestra total de 224 personas. El análisis y la codificación se realizaron utilizando los softwares Max Kyoda, SPSS y Smart PLS. Los hallazgos de la investigación mostraron que en este campo se extrajeron 8 temas y 61 subtemas, que incluyen los componentes de comportamiento, corrupción, comunicación, aspecto sociocultural, familia, respeto, legalidad y justicia, en este orden de importancia. En general, prestar atención a los aspectos de comportamiento y corrupción juega un papel importante en la mejora del estatus ético de los árbitros deportivos en Irán.

\section{PALABRAS CLAVE}

Ética; Arbitraje; Deportes; Irán.

\section{INTRODUCTION}

Today, sport and its various dimensions are considered as an important topic in various circles and as an efficient tool and a unique phenomenon to create a dynamic and vibrant society and solve many social, cultural and even economic and political crises (Salimi et al., 2012). Sport is one of the important social fields, which has a high potential for the emergence of ethical problems and issues due to having wide audiences (Brosnan, 2019). So that along with the social dimension, its legal, cultural and economic dimensions have also been highlighted; therefore, large budgets are spent for the development of sports and victory in the world arenas (Feiz, 2018). One of the special areas that has a specific importance in sports is ethics. Ethics is one of the most important topics in the present age that has a very close relationship with sports. Sport has the capability to overshadow cultural, social, economic, political and other issues in a society. Among all the above issues, sport faces a serious challenge called losing the spirit of sports and sports ethics in the sports community, which has specific cultural and social values (Khosravizadeh et al., 2009). 
Kalani et al.

In fact, all individual and social behaviors that are issued from athletes in sports and other social environments should be based on practical ethics (Shirali et al., 2016). Sports environments have always had a motivating force at the community level that attract many groups and individuals towards themselves. Most major researches about sports address ethical issues (Hughes, 2013). Ethics refers to the study of ethical judgments based on the values, beliefs, and attitudes that an individual or group has (Sinclair et al., 2016). Ethics is also a set of human traits that emerges as a behavior that results from the inner moods of human beings (Shah Ali et al., 2015). Ethics is a necessity of a healthy society, and due to the help of its positive individual, organizational and social functions and consequences, has always motivated the attention of researchers, coaches and managers of organizations and societies to try to maintain and promote its level (Eidi et al., 2016). Sports ethics means paying attention to the characteristics of good sportsmanship, fair and chivalrous competition in the sense of observing justice and participation in sports based on religious and legal beliefs (Abdullah Pour, 2016). Sports ethics refers to the ethical indicators and traits that champions have been required to observe in terms of technical and ethical rules in their field of sports, and failure to comply with them has negative consequences; among these traits are to maintain one's behavior during competition and anger, presenting fair play or, in general, the same characteristics that turn the champion into a hero (Fallah et al., 2009). Sports ethics is basically a concept that is attributed to the ethical and social values existing in sports and is also a description of behavior according to norms, rules and expectations (by the individual and the society) in the field of sports (Tajbakhsh et al., 2016). In sports, human resources have a determinant role and in all developmental and national programs have a special priority; for example, managers, coaches, referees, doctors, sports psychologists, experts, athletes, parents and sports fans have a pivotal role in the growth and evolution of athletes and also in sports ethics development. This point requires the adherence and observance of ethical principles and values by themselves and transferring these concepts to others (Khosravizadeh, 2019). These ethical principles can be a starting point for increasing ethics in the organizations, and success is achieved when the proper conditions are established in the place (Waegeneer et al., 2016).

Sports ethics is one of the topics of applied ethics that is used to measure practical ethical decisions and faces ethical issues, behaviors and policies in the professions, and governments (Kalshoven et al., 2011). Today, there are discussions about the need to change the attitude towards the issue of ethics in sports among the sports community (Rahmati et al., 2014). Sports immorality occurs when an inappropriate or unethical movement occurs by an athlete, coach, referee, or spectator on the playground, and the person is often unaware of his incorrect behavior, and this misbehavior is due to the ignorance, and in general, ethical issues in the field of sports (including taking bribes, 
breaking rules, racism, fraud, and so on) (Sample et al., 2019). An example of this unethical behavior at the London Olympics Games (2012) occurred when the World Badminton Federation disqualified several athletes because of violating ethical rules for competitions; this point shows how ethical rules have gained credibility and authority in the field of sports (Schwartz, 2012). Some of the reasons for unethical behavior by athletes, coaches, and managers include: 1 . Excessive emphasis on victory that has caused the emergence of the concept of victory at any cost, 2. Gaining fame and economic benefits in sports, 3. Pressure by spectators and managers to achieve higher quality levels, 4 . Lack of emphasis on athletic spirit and the importance of teamwork at the amateur level, 5. The commercialization of sports, and 6- Excessive emphasis on the importance of the role of sports at society level that generally justifies achieving success at any cost (Mohammadi, 2015).

One of the effective tools for controlling these ethical behaviors of athletes, coaches and referees is to use an ethical code or regulation (Moradiani Farsani, 2017). It is among the tools that, by compiling it, sports managers, coaches and referees can achieve useful instruction for the realization of ethical ideals, goals and ethical standards (Tajbakhsh, 2014; 45). Accordingly, numerous sports organizations have set up ethical regulations for certain groups of audiences, coaches, and athletes (Morasaie, 2014). In fact, one of the most common tools for operationalizing professional ethics is ethical and behavioral codes, so that compiling, training, and monitoring to follow professional ethics codes have become customary in many countries of the world, and each one of the national and international professional organizations have compiled and approved some codes (Stoeber, 2016). Managers with ethical concerns have spent their effort preparing a list of behavioral musts and must nots. Observance of these musts and must nots is a guarantee of the virtuous behavior of business owners and employees in that business. These musts and must nots draw the pattern of communicational behavior of the organization's people with each other and also with the customer, client and other stakeholders (in various situations) (Yabloui et al., 2016). The lists of ethical requirements and obligations, which are compiled in the form of musts and must nots, are often called behavioral codes or ethical regulations (Gharamaleki, 2018).

After the coaches and athletes, the referees are those who have the most difficult sports duties and are the third pillar that composes the sports competitions. Good judgment facilitates holding sports events, and in this case, the skills of the players and the tactics of the team determine the outcome of the match. On the contrary, poor judgment reduces the value of the event and reduces the enjoyment of players, coaches and spectators. If referees make a mistake, all the criticism will be directed towards them, but if they show their best performance during the execution of the competition, they will not be noticed (Ramazaninejad et al., 2017). In any case, the referees receive less public attention. Therefore, 
Kalani et al.

judging and refereeing in sports is a challenging and exciting job due to the struggling nature and the spirit of the sport. The occupation of refereeing in most sports fields is always associated with stress and anxiety. Hence, referees should be able to withstand such stresses so that unethical behaviors do not appear in them (Zelyurt et al., 2017).

Kavussanu (2019) investigated the aggressive behaviors of athletes in the last ten years, focusing on behaviors that have adverse interpersonal consequences or violate fair play ideals, including aggression, fraud, doping, and antisocial behaviors toward opponents and teammates. Pizzi and Stanger (2019) also found out that ethical behaviors toward teammate players as well as opponent players improve team performance and efficiency. On the other hand, Graupensperger et al. (2018) found out that ethical behaviors lead to greater coherence of teammate players in ice hockey players, and also reduce antisocial behaviors in them. Simon (2016) also examined ethical issues in the Turkish sports media in his research, and the research results showed that the sports media have not been loyal to ethical codes and repeatedly violated ethical codes. Therefore, this point confirms the fact that the sports media is an influential factor in the development of ethics. In the report of Rosa (2015) the ethical codes proposed in Portugal sports were equal opportunities, respect, health, enjoyment of effort, fair play, respecting others, striving for superiority and balance between body, interest and mind. Hajipour et al. (2009) showed that determining specific ethical and functional goals can motivate or guide the contexts for the emergence of sports ethics. Also, for the formation of ethical behavior, objective contexts, and actual performance can have deeper effects than cognitive and subjective contexts. Zareieyan et al. (2017) showed a physical education ethical charter capable of being explained in the form of six factors of law-based behavior, group work, verbal honesty and behavioral justice, financial responsibility, professional and conscientious behavior.

Sport is understood as a tool for lifelong learning and can be seen as a means to improve the status in life span. Thus, sport as a whole is not limited only to the unique characteristics of people's biological and physical potential, but also shows a set of complex and systematic characteristics, a social and ethical relationship and common natural characteristics (Isidori et al., 2015). In the sports profession, the management of sports and the responsibility of athletes towards the right owners is called sports ethics. That is, if athletes, as well as guide managers and technical staff in sports, are aware of their own ethical responsibilities towards the right owners in sports environments and adhere to these responsibilities in practice, then ethics and sports are realized. Any type of unethical behavior is a serious obstacle to the development of sports. If we are required to observe ethics in judgements and other areas of sports, then competition is converted to an opportunity for the growth and development of sports. Conversely, it can become a threat for the decline of sports (Qaramaleki, 2017). 
Kalani et al.

Football refereeing, as one of the main pillars of football, has been effective in the growth and development of football and has allocated a special and determinant position in football to itself. The role of refereeing in the football industry is very determinant, and a wrong decision may have devastating effects on clubs. As football referees are responsible for monitoring and judging the actions and mistakes of the players and are considered as an essential part of the football match, it is very important to investigate their performance (Ghasemi et al., 2009). In recent years, the imposed demands on high-level football referees have significantly increased. The importance of the perceived duty in refereeing is such that referees must judge by determination and correct and ethical decision-making along with accepting responsibility. Therefore, referees' decision making can have a determinant role in sports (Furley et al., 2013).

Today, topics are proposed about the necessity of changing the attitude towards the issue of ethics in the country's sports among the sports community, and the ethical problems of a number of athletes, especially of football type, have been converted to one of the problems for sports managers. Before addressing the issue of ethics, it should be considered that ethics is inherently a neutral phenomenon and the only positive aspect of it is politeness. When we talk about the need for the existence of ethics in the sports domain, it should be clear what sport really means.

In recent years, ethical regulation or code has been compiled in Iran and various forms of it are being formed in various sports. At present, sports regulations have been written in some sports fields, but in the refereeing domain, due to its nature, no research has been done in this field yet. Regarding the importance of ethical regulations in sports organizations, especially in sports refereeing, it is now more important than ever. Therefore, in this research, we aimed to identify and prioritize the factors affecting the Iranian Sports Refereeing Ethics Code.

\section{METHODS}

In this research, from the approach perspective, in order to compile the sports refereeing ethical code in Iran, the mixed research method was used. In the first step, the qualitative method of content analysis was used, and to test the model the quantitative descriptive-analytical method of correlation type based on the structural equations model was used. Also, exploratory research projects were used because the researchers were pursuing to find a field about an indefinite situation under the title of compiling sports refereeing ethical code in Iran. For this purpose, the researchers first identified the phenomenon and collected qualitative data through exploratory interviews, and then tested the model extracted from sports refereeing ethical code in Iran by compiling a model and collecting quantitative data. 
The statistical population of this research consisted of domestic and foreign documents, sources and reference books available in the field of subject matter, officials and informants of the sports refereeing ethical code in Iran. In the first part (qualitative) to conduct the field interview, the statistical population of the research included the officials and informants of the sports refereeing ethical code in Iran. These individuals were selected by the snowball sampling method for qualitative interviews on the research topic. In the second part (quantitative), after collecting information obtained from qualitative research, the questionnaire was made and this questionnaire was randomly distributed among the referees and assistant referees of the premier leagues of team sports (including football, volleyball, handball and basketball) and individual sports (including taekwondo, karate, wrestling and swimming). The population and the sample are reported separately in Table 1. According to the purpose of the study, participants were selected based on snowballs sampling among experts in sports ethics and refereeing in the country. The process of selecting samples continued until no new data emerged during the acquisition of information; in other words, the data reached saturation in 14 interviews, and the continuation of the interview was carried out only to ensure the findings. In this research, 16 interviews were conducted with 15 informants and experts (the interview was conducted twice with one of them).

Table 1. Statistical population and sample in the research quantitative section

\begin{tabular}{lccc}
\hline \multicolumn{1}{c}{ Statistical Group } & Sports & $\begin{array}{c}\text { Population } \\
\text { Number }\end{array}$ & $\begin{array}{c}\text { Sample } \\
\text { Number }\end{array}$ \\
\hline Referees and assistant referees of team sports in & Football & 72 & 48 \\
the Premier League & Volleyball & 38 & 25 \\
& Handball & 42 & 28 \\
& Basketball & 40 & 26 \\
\hline \multirow{2}{*}{ Referees and assistant referees of individual } & Taekwondo & 27 & 21 \\
sports in the Premier League & Karate & 33 & 26 \\
& Wrestling & 35 & 27 \\
& Swimming & 29 & 23 \\
\hline Total & - & 316 & 224 \\
\hline
\end{tabular}

Therefore, the total number of participants of the present research was 224 people and the sampling method was stratified-random. The data collection tool consisted of a semi-structured interview in the qualitative section and a researcher-made questionnaire in the quantitative section. In the qualitative section, the interview was used to identify the desired factors and these factors were identified in this section. In the quantitative section, the questionnaire was used, which was divided into two general sections: demographic characteristics and its questions, which were in the form of 5value and 61 questions. The questionnaire was then used to obtain more accurate information. The 
Kalani et al.

elements considered for each one of the factors, as well as their corresponding questions in the questionnaire, are presented in Table 2.

Table 2. Questionnaire questions and its components

\begin{tabular}{cc}
\hline Components & Questions \\
\hline Legality & $1-7$ \\
Respect & $8-10$ \\
Behavioral & $11-26$ \\
Communicational & $31-37$ \\
Corruption & $32-34$ \\
Justice & $35-38$ \\
Sociocultural & $39-54$ \\
Family & $55-61$ \\
\hline
\end{tabular}

The confirmation of the validity, research accuracy, reliability, and data confirmation capability were investigated. To ensure validity, the findings of this study were presented to the participants and they expressed their views about the coordination of the findings with their experiences to researchers, as well as a deep participation about the emerged themes by the research group at various stages of the study. By maintaining the documentations at all stages of the research, the researchers ensured the confirmation capability of this research. Researchers' interest in the phenomenon under study, longterm contact with the data, as well as effort to obtain the opinions of others in this field were other factors that ensured the confirmation capability. In the present research, the reliability of the measurement model was evaluated and confirmed by factor load coefficients, Cronbach's alpha and composite reliability. Thus, all factor loads were higher than 0.50 and the Cronbach's alpha and the composite reliability of all components were higher than 0.70 . The factor load was calculated by calculating the correlation value of the indicators of one structure with that structure. If that value was equal to or higher than 0.4 , it confirmed that the variance between the structure and its indicators was higher than the variance of the measurement error of that structure, and the reliability about that structure was also acceptable, point that was also confirmed. Regarding both the questions form (interview) and the final questionnaire for distribution, the content validity was examined, using the opinions of ten professors. Therefore, the content validity of the research tools was confirmed. Divergent and convergent validity, which are related to structural equations, were measured and confirmed. In the present research, the statistical method of structural equations was used to validate the model and to present the final model. Structural equation model is one of the main methods of analyzing complex data structures and means analyzing various variables that in a structure based on theory show the simultaneous effects of variables (direct and indirect relationships) on each other. 
Kalani et al.

\section{RESULTS}

The interviewees in this research were 15 people selected as sample, of which 14 were males and 1 was female. Also, 5 people had bachelor degree, 1 individual had master degree, and 9 people had Ph.D. degree. Furthermore, among them 7 people had refereeing job, and 8 were faculty members of the university.

In the quantitative section, the results showed that $12.9 \%$ of sports referees had an experience of 6-11 years, $49.2 \%$ had an experience of 12 to 15 years, and $37.9 \%$ had an experience of more than 16 years. Regarding age, $2 \%$ were younger than 30 years old, $69.2 \%$ were between 31 and 40 years old, $26.8 \%$ were between 41 and 50 years old, and $1.8 \%$ were older than 51 years old.

In the structural part, we first examined the normality of data distribution (Table 3).

Table 3. Skewness and Kurtosis results in order to investigate the normality of data distribution

\begin{tabular}{cccccc} 
& \multirow{2}{*}{ Sample } & \multicolumn{2}{c}{ Skewness } & \multicolumn{2}{c}{ Kurtosis } \\
\cline { 3 - 6 } & & Statistics & Error & Statistics & Error \\
\hline Legality & 224 & 2.102 & 0.208 & 1.520 & 0.183 \\
Respect & 224 & 1.302 & 0.208 & 1.125 & 0.183 \\
Behavioral & 224 & 1.085 & 0.208 & 1.658 & 0.183 \\
Communicational & 224 & 1.320 & 0.208 & 0.985 & 0.183 \\
Corruption & 224 & 3.520 & 0.208 & 5.658 & 0.183 \\
Justice & 224 & 1.210 & 0.208 & 1.201 & 0.183 \\
Sociocultural & 224 & 1.325 & 0.208 & 1.568 & 0.183 \\
Family & 224 & 0.980 & 0.208 & 1.784 & 0.183 \\
\hline
\end{tabular}

The results of Table 3 showed that the Kurtosis is located between 5 and -5 , but the Skewness is not located between 3 and -3 (in the corruption variable). Therefore, the data does not have a normal distribution. Although the theoretical foundations confirm the research model, since it is a new model and has not yet matured, PLS variance-based software was used. Figures 1 and 2 show the fit of the structural model and the significance coefficients. 
Kalani et al.

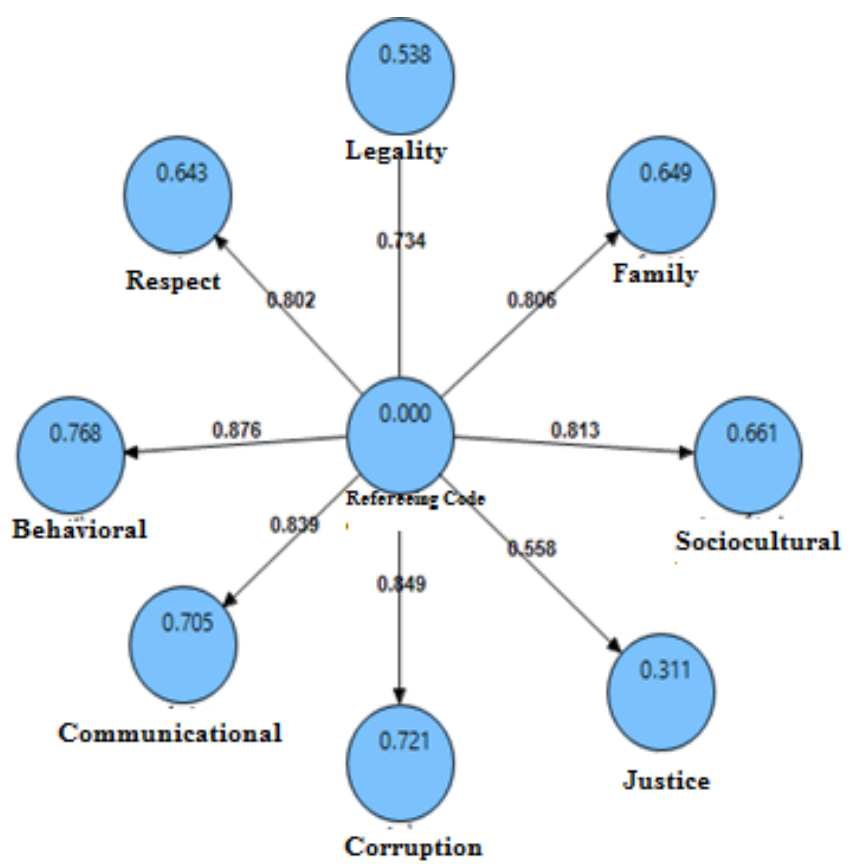

Figure 1. Fit of the structural model

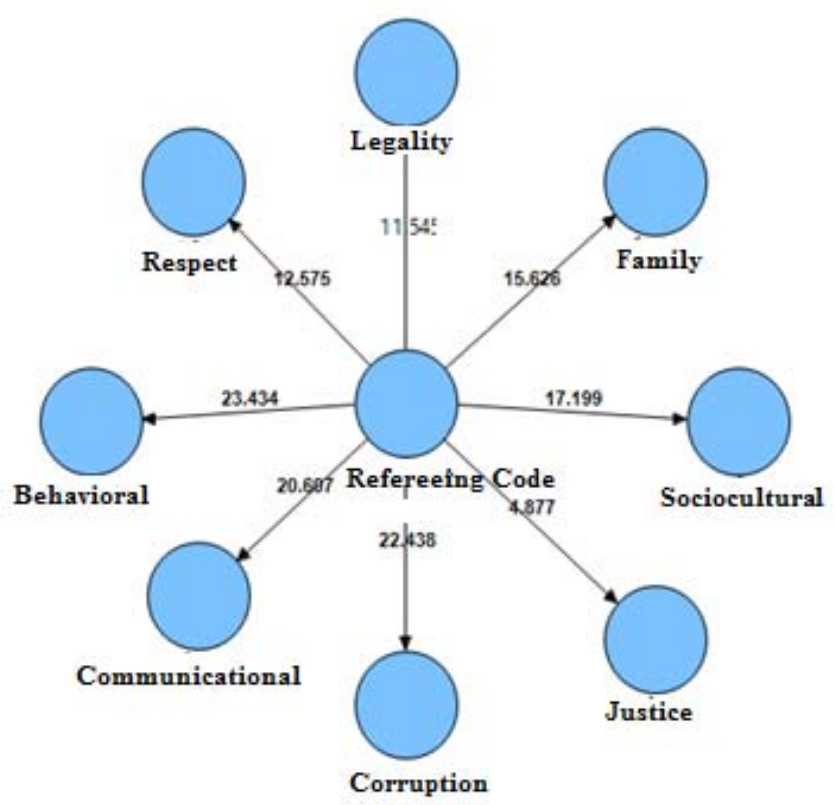

Figure 2. Significance coefficients

According to Figures 1 and 2, the T-Values for the 8 relationships related to research hypotheses were higher than 0.95 , and all the relationships were confirmed. This means that the model has a proper fitness. T-Values are also presented in Table 4. 
Table 4. T-Values

\begin{tabular}{cc}
\hline Components & T-Value \\
\hline Legality & 11.545 \\
Respect & 12.575 \\
Behavioral & 23.434 \\
Communicational & 20.607 \\
Corruption & 22.438 \\
Justice & 4.877 \\
Sociocultural & 17.199 \\
Family & 15.626 \\
\hline
\end{tabular}

According to the three values of $0.01,0.25$ and 0.36 , which were introduced as weak, medium and strong values for GOF, values higher than 0.36 were obtained in the 8 variables, which indicates the overall strong fit of the model (Table 5).

Table 5. Fit of the general model

\begin{tabular}{cccc}
\hline Component & R Square $\left(\mathbf{R}^{\mathbf{2}}\right)$ & Commonality & GOF \\
\hline Legality & 0.538 & 0.754 & 0.658 \\
Respect & 0.643 & 0.654 & 0.384 \\
Behavioral & 0.768 & 0.648 & 0.658 \\
Communicational & 0.705 & 0.715 & 0.749 \\
Corruption & 0.721 & 0.775 & 0.503 \\
Justice & 0.311 & 0.798 & 0.669 \\
Sociocultural & 0.661 & 0.634 & 0.783 \\
Family & 0.649 & 0.843 & 0.425 \\
\hline
\end{tabular}

Based on the obtained path coefficient value, the factors affecting the Iranian Sports Refereeing Ethics Code were ordered, according to their importance, as follows: behavioral, corruption, communicational, sociocultural, family, respect, legality and justice (Table 6).

Table 6. Prioritizing the factors affecting the Iranian Sports Refereeing Ethics Code

\begin{tabular}{cc} 
Factors & Priorities \\
\hline Behavioral & First \\
Corruption & Second \\
Communicational & Third \\
Sociocultural & Fourth \\
Family & Fifth \\
Respect & Sixth \\
Legality & Seventh \\
Justice & Eighth \\
\hline
\end{tabular}




\section{DISCUSSION}

This research was conducted with the aim of identifying and prioritizing the factors affecting Iran's sports refereeing code. In the qualitative part of the research, it was specified that the 8 components of legality, respect, behavioral, communicational, corruption, justice, sociocultural and family are the components of the refereeing ethics code in sports. In the quantitative part, the research components were also confirmed. It should be stated then that, based on the obtained path coefficient value, the components of behavioral, corruption, communicational, sociocultural, family, respect, legality and justice are respectively the most important components of the referring ethics code in the Iran's sports. The results of the present research are not consistent with the results of the researches of Moradian Farsani et al. (2019), Khosravi Zadeh et al. (2019), Baran Cheshmeh and Afarinesh Khaki (2015), Taghizadeh (2014), Graupensperger (2018), Neshati (2014), Bozorgzad Moghim (2014), Moradian Farsani et al. (2012) and Poursoltan Zarandi et al. (2012). The reason for the difference in the order of the components identified with previous research is the difference in the statistical population. In none of the conducted researches, the code of referring ethics was examined. Therefore, based on the prioritization and the importance ratio of each component, we interpret them.

Among the components extracted from the present research, the first priority was given to the behavioral component. The indicators of this component include: they should have comfort, they should control their emotions, they should treat the players seriously, they should help the ethical development of other referees, they should be self-controlled and they should be able to keep calm and control their behaviors, they should avoid humiliating players during the game, they should avoid using inappropriate words, they should not threaten the players, they should not humiliate the players, they should control their emotions resulted from winning or losing the match, they should treat players with kindness and affection, they should not shout at players, they should create an ethical model for those who are interested in refereeing, they should prevent players from getting angry, they should have appropriate clothing (appearance status), and they should accept their mistakes. Pizzi and Stangar (2019) stated in their research that ethical behaviors towards teammate players as well as opponent players lead to the team efficiency and performance improvement. In fact, the observance of behavioral factors towards others (fans, athletes, coaches, athletes' families, and so on), by the referees, leads to the growth of ethics in the sports environment. The results of this research in this section are consistent with the results of Hajipour et al. (2019) and Pizzi (2019). Therefore, the Iran's sports referees are recommended to use appropriate behavioral factors when dealing with people in sports environments. Therefore, considering the results of the present research, indicating the importance of behavioral 
factors affecting the code of sports referees, it is suggested that in selecting sports referees, while paying attention to their personal characteristics, it should be tried to select referees with strong personal characteristics as well as with the capability to overcome environmental problems.

Corruption is the next area related to the ethics in referring. The indicators of this area include: they should avoid taking bribes, they should not collude, and if they are aware of players' collusion, they should report it. Shafiee and Afroozeh (2018) stated in their research that referees can lead to corruption in sports by applying collusion to win in the competitions. In fact, corruption in sports has always been among the major topics in scientific and sports circles. Many researches have been done regarding why this phenomenon occurs, but Iran's sports are still witnessing this phenomenon in the arenas of sports competitions. In recent years, there have been attempts to use assistive devices because of the problems of corruption created in sports, including the use of Video Assistant Referee (VAR). However, this tool, which is used in football stadiums in other countries, is very expensive (more than 300,000 dollars for each stadium), but it can be used as one of the ways to prevent corruption in sports. Another way that is recommended to the country's sports authorities is to deal decisively with the trespassing referees. Nevertheless, the enactment of deterrent laws has more positive consequences than dealing with them decisively. Based on the results of the present research indicating the importance of corruption factors affecting the code of sports referees, it is suggested that, by creating corruption committees in the refereeing department, the performance and activities of referees in sports events and matches are monitored.

Another component extracted from the present research is the communicational component. The indicators of this component include: they should establish a proper relationship with the athletes and coaches of the teams under refereeing, they should listen to the players' talk well, they should have the necessary flexibility in dealing with the players, they should talk with the players and understand them, and they should empathize with the players, coaches and supervisors by establishing communication. Communicational skills are skills that have a role in interpersonal interactions and the communication process; the most important of these skills include verbal skills, listening, and effective feedback (Yukl, 2008). By equipping referees with communicational skills, the emergence of many ethical and behavioral abnormalities can be prevented, both by the referee and by athletes, spectators, and coaches, so it is necessary for referees to have communicational skills. Nazari and Salehi (2017) stated in their research that, if the referees have appropriate communicational skills, their efficiency increases. On the other hand, Davarzani and Naemi (2018) stated in their research that communicational skills affect professional ethics. The results of the present research in this section are consistent and in line with the results of the researches of Khosravizadeh et al. (2019), Nazari and 
Salehi (2017) and Davarzani and Naemi (2018). Therefore, the Iran's sports managers and those in charge of refereeing affair in the country's sports are recommended to try to improve the communicational skills of the referees or to select those referees for judgement in the competitions who have appropriate communicational skills. Also, in the process of participating in refereeing courses, they should dedicate a headline to the techniques of communicational skills in refereeing. Based on the results of the present research indicating the importance of communicational factors affecting the code of sports referees, it is suggested that, in the process of participating in the refereeing courses, a headline is devoted to the techniques of communicational skills in refereeing. It is also suggested that, while the referees attend activities outside the sports environment, a constructive relationship should be established between the referees and the community.

Sociocultural factors are also other identified factors in the refereeing ethics code. The identified indicators of this factor are: they should consider the cultural differences of the players in the playground, in terms of behavior in the society they should be as a model, they should behave in a way that they are respected in the society, they should have decency in speech, they should have social behaviors and communications, they should be trustworthy to the people, they should observe the social and Islamic culture and traditions, they should have social acceptance among the people, they should have self-esteem in social behaviors to deal with social issues and problems, they should be selfsufficient, they should observe social discipline and order, they should have stability of opinion (in speech and behavior) in social interactions, and they should establish positive and appropriate communications with colleagues in occupational and social environments. Also, they should observe politeness and respect in dealing with others, they should have a correct and logical judgment in dealing with various social issues, they should have appropriate ethics with the media, and observe ethics in cyberspace. There are many cultural and social factors that can reflect the ethics of the referee, both in and out of the sport environment. Understanding people's cultural differences (on the match ground) is one of these cases. The cultural differences of people lead to different reactions in facing with a similar action. By recognizing these differences, the referee can show an appropriate reaction of himself. Observance of social norms in society and in cyberspace is another issue. The results of the research in this section are consistent and in line with the research results of Halabian et al. (2014). Therefore, those in charge of refereeing in sports are recommended to warn their referees about the observance of sociocultural factors. Based on the results of the present research indicating the importance of sociocultural factors affecting the code of sports referees, it is suggested that, by improving the referees' expenses and also by promoting the regular payment of these expenses to the referees, the referees' 
Kalani et al.

social status is promoted. It is also suggested that it is equated with the referees' wages in various fields and approximate to its normal form and international standard.

The family factor is among the factors influencing the refereeing code of ethics. Identified indicators of this factor include: they should be a model in their family environment, they should respect their spouse, children and relatives, they should have self-sacrificing towards their family, they should be loyal to their spouse and children, they should be conscientious about their family for their duties, they should consider enough time to be with their family, and they should not transfer refereeing issues to the family environment. Referees can have a significant role in society and should be a model in their family environment too. Therefore, it is recommended that referees control their family circumstances, so that they can show good morals of themselves in the competition environment. Thus, as Safari Jafarloo and Ghorbani (2018) stated in their research, ethical values can be developed through educational, research, sports, informing, as well as managerial strategies. With the development of ethical behaviors by those involved in sports and especially referees, the improvement of the performance of the entire sports system of the country can be witnessed (Pizzi and Stangar, 2019). Ethical behaviors also lead to greater coherence (Graupensperger and Tisak, 2018, Bermejo et al., 2018). Therefore, in general, the sports managers and sports referees in Iran are recommended to use the principles of the present code in order to improve the ethical factors in the sports environment.

Another result of the present research was to observe respect as one of the pillars of the refereeing ethics regulations in sports. The indicators of this variable include: they should respect the coaches of both teams, they should respect the spectators and avoid provoking them, and they should respect the individual and human rights of the players. Rosa (2015) stated rules and regulations, equal opportunities, respect, health, enjoyment of effort, fair play, respecting others, striving for superiority and balance between body, interest and mind in his research. Eidi et al. (2016) in their research emphasize the factor of respect, as one of the pillars of the professional ethics questionnaire of sports coaches. Razzaghi et al. (2014) determined the validity and credit of the Persian version of the championship character questionnaire. The results showed that this scale had five factors: respecting social relations, respecting laws and officials, commitment to the sport that is being performed, respect and attention to the opponent, and the lack of a negative approach to sports performance. Therefore, the results of the present research in this section are consistent and in line with the results of the researches of Eidi et al. (2016), Baran Cheshmeh and Afarinesh Khaki (2015), Taghizadeh (2014), Razzaghi et al. (2014), Neshati (2014), Bozorgzad Moghim (2014), Moradian Farsani et al. (2019), and Rosa (2015). Therefore, those in charge of refereeing in sports are recommended to oblige referees 
to respect all these aspects. For this purpose, they can make continuous and consistent evaluations for the referees and encourage competent referees.

Legality was one of the factors in the refereeing ethics regulation in the Iran's sports. The indicators of this variable include: they should be present on time for refereeing at the time of the match, they should not be afraid of executing the rules, they should not think about the consequences of enforcing the rules, they should just be the executor of the rules, and they should guide and encourage the players to observe the rules. However, many referees do not have sufficient knowledge related to their legal duties (Mir Safaian and Mohammadi Nejad, 2018). Also, their performance in respect of performing legal duties related to the refereeing profession has not been evaluated in a proper competition environment. In general, the results of the present research are consistent and in line with the results of the researches of Rosa (2015), Khosravizadeh et al. (2019), Mir Safian and Mohammadi Nejad (2018) and Mir Safian (2017), who in their research examined the legal issues of refereeing in various sports fields and the importance of these issues in refereeing. Also, it is consistent and in line with the researches of Baran Cheshmeh and Afarinesh Khaki (2015), Taghizadeh (2014) and Moradian Farsani et al. (2019), who refer to legality as one of the pillars of the ethical regulation in sports. On the other hand, Asgari et al. (2013) stated in their research that ethics has an important role in preventing lawlessness. Halabian et al. (2014) identified and prioritized ethical criteria in the professional sports of Iran, dividing ethical criteria into educational, psychological, legal, economic and sociocultural criteria. Also, they included components such as not insulting the opponent on the field of match, legality, teaching ethical values from the first days of beginning sports, not paying bribes and financial collusions, and avoiding excessive selfishness and pride as the ethical criteria in the professional sports. Therefore, according to the results of the research in this section, those in charge of refereeing affair in various sports fields are recommended to comply with the rules of refereeing through adopting laws.

Ultimately, justice is the next factor identified about the refereeing code of ethics. The indicators of this factor are: they should not discriminate between the teams under their refereeing (ethnic, racial, social, family, and so on), they should treat players equally, and the punishments should be commensurate with the foul committed. Adherence to justice in sports judgments by referees leads to the creation of an atmosphere of calmness and non-tension inside and outside of the field of match. In fact, observing justice for the referee, like a judge, is among the rules of judgment (Mansouri Fayyaz, 2012). The results of research in this section are consistent and in line with the results of the researches of Neshati (2014), Bozorgzad Moghim (2014) and Moradian Farsani et al. (2009). Therefore, those in charge of refereeing in sports are recommended to provide the conditions for assuring justice in 
Kalani et al.

refereeing. Also, the differences in the wage of referees in various fields and the differences with other countries lead to the frustration of the referees, which in turn can lead to injustice in their judgment. Thus, the sports managers must provide appropriate financial and social contexts for the referees.

\section{CONCLUSIONS}

Research findings showed that the main factors affecting the Iranian Sports Refereeing Ethics Code were behavior, corruption, communication, sociocultural aspect, family, respect, legality and justice, in this order of importance. In general, paying attention to the behavioral and corruption aspects plays an important role in improving the ethical status of sports referees in Iran.

\section{REFERENCES}

1. Abdullah Pour, H. (2016). The importance of Ethics in Sports. Second National Conference on Sports Sciences and Physical Education of Iran, Association for the Development and Promotion of Basic Sciences and Techniques.

2. Asgari, A., Ibrahim, N., \& Ghodratullah, M. (2013). The Role of Ethics in Preventing Lawlessness. Biological Ethics, 9, 122-143.

3. Baran Cheshmeh, M. A., \& Afarinesh Khaki, A. (2015). Designing and Compiling the Ethical Regulations of the Sports Teams of the Arm Forces of the Islamic Republic of Iran. Journal of Education in Police Sciences, 2.

4. Bermejo, J. M., Borrás, P. A., Haces Soutullo, M. V., \& Ponseti, F. J. (2018). Is fair play losing value in grassroots sport? Journal of Sport Psychology, 27(Suppl. 3), 1-5.

5. Bozorgzad, M. (2014). Designing and Compiling Ethical Regulations in the Field of Badminton. Master Thesis, Islamic Azad University of Taft.

6. Brosnan, S. (2019). The impact of sports participation on crime in England between 2012 and 2015. Sport in Society, 1-12. https://doi.org/10.1080/17430437.2019.1631805 Codes of Ethics. Procedia-Social and Behavioral Sciences, 83, 161-164.

7. Davarzani, M., \& Naemi, A. M. (2013). The Effect of Communicational Skills Training with Religious Approach on Professional Ethics and Job Negligence of the Employees of Sabzevar Medical Sciences. University of Medical Sciences, 25(2), 143-150.

8. De Waegeneer, E., Devisch, I., \& Willem, A. (2016). Ethical Codes in Sports organizations: An Empirical Research on Determinants of Effectiveness. Ethics \& behavior, 1-22.

9. Eidi, H., Shabani Moghadam, K., \& Amiri, J. (2016). Normalization of the Questionnaire of the Professional Ethics of Sports Coaches. Applied Researches in Sports Management, 5(1), 11-21.

10. Fallah, Z., Soltan, A. T., Javanmard, M., \& Fallahnejad, A. (2020). Investigating the Factors Affecting Ethical Crime in Tehran Sports Clubs. Criminal Intelligence Researches, 12(14), 3552.

11. Feiz, Z. (2018). Sports Behavior and the Ethical, Civil Responsibility of Athletes From A Jurisprudential and Legal Perspective. Organizational Behavior Management Studies in Sports, 5(2), 105-116.

12. Furley, P., Bertrams, A., Englert, C., \& Delphia, A. (2013). Ego depletion, attentional control, and decision making in sport. Psychology of Sport and Exercise, 14(6), 900-904.

13. Gharamaleki, A. R. (2018). Professional Ethics. Publication of Nashr-e Majnoon, 12.

14. Gharamaleki A. R., \& Faramarz, M. (2017). Organizational Ethics, Publication of Saramad, 5. 
15. Ghasemi, H., Farahani, A., \& Iraji Naghandar, R. (2019). Designing the model role Social exchange on responsibility of AFC elite football and futsal referees. Scientific Journal of Organizational Behavior Management in Sport Studies, 6(3), 67-79.

16. Graupensperger, S. A., \& Tisak, M. S. (2018). Moral behavior in the locker room predicts perceptions of task cohesion in youth ice hockey player. Journal of Human Kinetics, 65, 273 280.

17. Hajipour, A., Hamidi, M., Sajjadi, S. N., \& Khabiri, M. (2019). The Relationship Model of Self-Determination Motivation with the Sports Ethics of Elite Athletes of Iran (Case Study, First League of Iranian Football). Sports Psychology Studies, 27, 19-40.

18. Hughes, D. (2013). Organized crime and drugs in sport: did they teach us about that in medical school? British Journal of Sports Medicine, 47, 661-662.

19. Isidori, E., \& Benetton, M. (2015). Sport as Education: Between Dignity and Human Rights. Procedia-Social and Behavioral Sciences, 197, 686-693.

20. Kalshoven K., Den Hartog D. N., \& De Hoogh A. H. B. (2011). Ethical leader behavior and big five factors of personality. Journal of Business Ethics, 100(2), 349-366.

21. Kavussanu, M. (2019). Understanding athletes' transgressive behavior: Progress and prospects. Psychology of Sport and Exercise, 42, 33-39.

22. Khosravizadeh, E., Khalaji, H., Mandalizadeh, Z. (2019). Compiling the Ethical Charter of the Coaches of Sports Boards of Markazi Province. Journal of Human Resource Management in Sports, 2, 357-374.

23. Mansouri, F. F. (2012). Refereeing and the Responsibility of Referees in Sports Competitions from the Perspective of Islamic Jurisprudence and Law [Master Thesis]. University of Theology and Islamic Studies.

24. Mir, S. H, \& Mohammadinejad, A. (2018). Investigating the Attitude, Knowledge and Performance of Referees in Full of Collision Sports in Relation to Legal Issues Related to the Refereeing Profession. New Approaches to Sports Management, 6(22), 37-52.

25. Mohammadi, A., \& Ahmadi, E. (2015). Recognizing the Reasons for the Emergence of Unethical Behaviors among Athletes in Zanjan Province. First National Conference on Physical Education and Sports Sciences, Tehran.

26. Moradian F. F. (2017). Compiling Ethical Regulations for Athletes of the Wrestling Federation of the Islamic Republic of Iran [Master Thesis]. University of Ahvaz.

27. Nazari, R., \& Salehi, A. (2017). Presenting the Structural Equations Model of the Effect of Communicational Skills on Refereeing Skills and the Efficiency of Referees in the Iranian Football Premier League. New Approaches in Sports Management, 5(16), 49-60.

28. Neshati, H. (2014). Designing and Compiling the Ethical Regulations of Swimmers in Yazd Province [Master Thesis]. Islamic Azad University, Taft Branch.

29. Palou Sampol, P., Bermejo Díaz, J. M., Borràs Rotger, P. A., \& Ponseti Verdaguer, F. J. (2020). Effects of an educational intervention regarding fair play on sports team coaches. Journal of Human Sport and Exercise, 15(2), 419-431.

30. Pizzi, G., \& Stanger, N. (2019). Consequences of teammate moral behaviour: Linking team moral norms with cohesion and collective efficacy. International Journal of Sport and Exercise Psychology, 1-17.

31. Poursoltani Z., Hossein E.B., \& Zareieyan, H. (2016). Designing the Ethical Regulations of the Academic Members of the Physical Education and Sports Sciences of Iran. Research Project of the Research Institute of Physical Education and Sports Sciences.

32. Rahmati, A., Afarinesh K., Akbar P., \& Zarandi, H. (2014). Designing and Compiling Ethical Regulations of Iranian Mountaineers [Master Thesis]. Islamic Azad University, Science and Research Branch, Faculty of Physical Education. 
33. Ramezani N., Rahim S., Shahram R., \& Rahim L. M. (2017). Relationship between Job Characteristics and the Satisfaction of Iranian Football Referees: The Mediating Role of Professional Commitment. Applied Researches in Sports Management, 1, 21-32.

34. Razzaghi, M.I., Mehrabi, Q., \& Honari, H. (2014). Determining the Validity of the Persian Version of the Sports Character Questionnaire. Sports Psychology, 9, 81-92.

35. Rosa, B. A. (2015). Ethics in Sport: Guidelines for coaches. Luso-Illyrian Institute for Human Development.

36. Safari J., H., Ghorbani, \& M. H. (2018). Qualitative Analysis of the Spread of Sports Ethical Values among Students. Sports Management, 9(4), 35-49.

37. Schwartz, M. S. (2013). Developing and sustaining an ethical corporate culture: the core elements. Business Horizons, 56(1), 39-50.

38. Shafiee, S., \& Afroozeh, H. (2018). Identifying and Explaining the Effective Components in the Emergence of Corruption in Iranian Football. Sports Management Studies, 47, 49-67.

39. Shah-Ali M., Rashid-Poor A., Kavoosi E., \& Etebarian A. A. (2015). Professional ethics model in Iran organizations. Urban Management Journal, 39, 393-406.

40. Shirali, R. Mehdipour, A., Azmasha, T. (2016). Investigating the Relationship between Adherence to Sports Ethics and the Group Coherence of Women's Sports Teams. Organizational Behavior Management Studies in Sports, 3(11), 11-18.

41. Simon, R. L. (2016). The Ethics of Sport: What Everyone Needs to Know. Oxford University Press.

42. Sinclair, J., Papps, E., \& Marshall, E. (2016). Nursing students' experiences of ethical issues in clinical practice: A New Zealand study. Nurse Education in Practice, 17, 1-7.

43. Stoeber, J., \& Yang, H. (2016). Moral perfectionism and moral values, virtues, and judgments: Further investigations. Personality and Individual Differences, 88, 6-11.

44. Taghizadeh, A. (2014). Designing and Compiling the Ethical Regulations of Zurkhaneh Sports in South Khorasan Province [Master Thesis]. Faculty of Physical Education and Sports Sciences.

45. Tajbakhsh, A. (2014). Model of Promoting the Level of Sports Ethics with the Approach of Islamic Ethics. Research Journal of Ethics, 25, 45.

46. Tajbakhsh, A. (2016). Ethics in Sports (Applied Ethics Special for the Fields of Physical Education and Sports Sciences). First Edition, Qom, Publication of Maaref.

47. Yabluie, B., Mostahfezian, M., Meshkati, Z. (2016). Relationship between Ethical Components and Personality Traits. Quarterly Journal of Ethics in Science and Technology, 11(1).

48. Yukl, G. (2008). How leaders influence organizational effectiveness. The Leadership Quarterly, 19, 708-722.

49. Zareieyan, H., Baran C., Mehr A., Fazel B., Mahmoud, \& Rasekh, N. (2017). Compiling the Ethical Charter of the Managers of Physical Education of the Armed Forces. Journal of Human Resources Management in Sports, 2, 207-217.

50. Zelyurt, M. K., \& Ataçocuğu, M. S. (2017). Social pressure factors aimed at football referees in Turkey: a research on the 2nd league, 3rd league and amateur league referees. Journal of Physical Education and Sport, 12(3), 107-116. 
Kalani et al.

\section{AUTHOR CONTRIBUTIONS}

All authors listed have made a substantial, direct and intellectual contribution to the work, and approved it for publication.

\section{CONFLICTS OF INTEREST}

The authors declare no conflict of interest.

\section{FUNDING}

This research received no external funding.

\section{COPYRIGHT}

(C) Copyright 2021: Publication Service of the University of Murcia, Murcia, Spain. 